\title{
UNIVERSITY COURSES IN MATHEMATICS AND THE MASTER'S DEGREE.
}

\section{PROVISIONAL REPORT OF THE AMERICAN SUBCOMMITTEE \\ OF THE INTERNATIONAL COMMISSION ON THE TEACHING OF MATHEMATICS.* \\ I. Preliminary Remarks.}

IN preparing this report the committee has found the greatest difficulty in securing reliable information on the various topics considered. Nothing of the kind has been attempted since Cajori's report of 1890, "On the Teaching and History of Mathematics in the United States." $\dagger$ Valuable as this is, it covers only the period of the beginning of graduate study; and except for two brief statistical notes in the Reports of the U. S. Commissioners of Education and scattered items of information in the Bulietin of the American Mathematical Society, there exists no published information on the development of graduate instruction in mathematics since 1890. The Committee has, therefore, been compelled to gather its material almost entirely at first hand, relying mainly on personal correspondence and on statements contained in catalogues and other publications of American universities. It is needless to say that only a limited amount of information can be obtained in the former way, while as for the latter, it is too frequently the case that the facts desired are either very hard to get at, or are not given at all.

Over thirty colleges and universities in the United States offer graduate work in mathematics, but less than fifteen have given a doctor's degree in that subject within the last five years. The following twenty-four offer courses of an advanced character and report three or more graduate students for the year

* International Commission on the Teaching of Mathematics. Committee XIV. - Graduate Work in Universities. Subcommittee 1-Courses of Instruction and the Master's Degree. Chairman, D. R. CurTIss, Northwestern University ; EDward KASNER, Columbia University; A. C. LUNN, University of Chicago. This report was submitted to the American Commissioners in November, 1910. The report of Subcommittee 3 was published in the November, 1910, BulletiN.

$\dagger$ U. S. Bureau of Education, Circular of Information No. 3,1890. 
1908-09 : Bryn Mawr, California, Chicago, Cincinnati, Clark, Colorado, Columbia, Cornell, Harvard, Illinois, Indiana, Iowa, Johns Hopkins, Michigan, Missouri, Nebraska, Northwestern, Pennsylvania, Princeton, Leland Stanford, Syracuse, Virginia, Wisconsin, Yale. To this somewhat arbitrary list the greater part of the statistics of this report refer, but even in the field thus limited it has been impossible to obtain entirely reliable information on all the points covered. Accordingly, though the numerical statements here given are believed to be in the main correct, it has seemed best not to give detailed statistics for any particular institution.

\section{Historical Sketch.}

Genuine graduate work in mathematics may be said to date trom the founding of Johns Hopkins University, and the assumption of his duties there by Sylvester, in the year 18761877. It is true that courses of an advanced character had previously been given in various institutions, notably at Harvard, where Benjamin Peirce taught for nearly fifty years and exerted a profound influence on American mathematical development; but this earlier work was never of an exclusively graduate character, and was carried on with frequent interruptions due to the lack of properly prepared students. Johns Hopkins was founded primarily as a graduate school and that department has always overshadowed the college. Its great success proved a powerful stimulus to advanced work along all lines in this country and led ultimately to the founding of separate graduate departments in most of the leading American universities.

The group of eight or ten whom Sylvester soon gathered about him, and their successors, carried something of their master's enthusiasm with them when they went out to other institutions, and in the course of a few years advanced instruction in mathematics was begun in a number of other colleges and universities. Almost as important were some of the indirect results of this influence; for although the development at Harvard was independent of the Johns Hopkins movement, it is significant that this was also the period when graduate work in mathematics was placed on a permanent basis at Harvard.

The course of lectures delivered at Johns Hopkins by Cayley in 1882 had fourteen regular attendants, and added materially 
to the force of this movement. After Sylvester's departure in 1883 his pupils and associates continued his influence. Cajori reports nearly a dozen institutions in which graduate instruction was offered in the decade 1880-1890. Among them he mentions specifically Harvard, Cornell, Princeton, Virginia, South Carolina, Texas, Michigan, and Wisconsin, as well as Johns Hopkins, and indirectly refers to the work at Yale.

After the departure of Sylvester and Cayley it was natural that the more ambitious students should wish to continue their work under other mathematicians of the same order. Hence we find that by 1885 a number of Americans were studying in Europe, mainly in the German universities. It was no new thing for an American to receive a doctor's degree abroad, but up to this time such cases had been relatively few. From 1885 to 1893 , however, American mathematical study continued more and more to derive its inspiration from the seminars of Leipzig, Berlin, and Göttingen. The period of English influence was replaced by one in which a German training was the greatest desideratum, and if a single man is to be designated as Sylvester's successor, it is probably correct to say that the majority of Americans who studied mathematics in European universities received their training at this time in the seminar of Klein. This period was marked by the institution of strong mathematical departments in the newly founded Clark University (1889) and the University of Chicago (1892) and culminated in the Mathematical Congress held at Chicago in 1893 during the World's Fair, and Klein's Evanston lectures.

By 1893 Americans trained abroad had become an influential, and later a controlling element, and from that time American mathematics stood on its own feet. At present doctor's degrees in mathematics obtained each year at home and abroad are about in the ratio of five to one. It is, however, true that many still go to the great universities of Europe, and it will be shown in a later section of this report that at least half of those giving graduate instruction in this country have studied abroad.

\section{Organization and Personnel.}

At present practically all of the leading American universities have organized their graduate work into a separate school or college. With two or three exceptions, however, there is no division of the teaching force into graduate and undergraduate 
faculties. In particular, the same department of mathematics gives both advanced and elementary instruction, though not all its members may participate in the former. The number of those who give no undergraduate courses is very small. The work of the department is usually directed by one of the professors, designated as the head or chairman.

An examination of publications of the twenty-four institutions mentioned in Section I shows that the total mathematical teaching force, not including student assistants, was 202 in the year 1908-1909. Of these 136 offered advanced courses, but probably a considerably smaller number actually gave such work, since it will appear in Section IV that the total number of graduate students specializing in mathematics at these institutions was less than 250. It thus seems that only about half the total teaching force at these institutions had a part in graduate instruction. It should be added, however, that in a number of cases large technological departments necessitate a great amount of elementary mathematical work and increase the number of instructors who must devote all their time to such courses. In only two or three institutions was advanced work given by every member of the department.

A further inquiry as to the amount of advanced work given by the 136 instructors mentioned in the preceding paragraph shows that 45 undertook courses announced as primarily for graduates amounting to more than three hours per week. In only five universities were there four or more men offering more graduate work than this, while in ten there was either only one, or else no member of the department who offered more. It thus appears that the greater part of advanced instruction is in the hands of about one fifth of the total teaching force. Naturally these are the older men, as a rule, but it is also evident that a considerable number of others give a limited amount of graduate work. In many institutions each of the younger instructors offers a single graduate course.

In the past the complaint has frequently been heard that American professors are overburdened. That this is still the case, even with men giving a considerable amount of advanced work, is evident from the fact that 9 of the 45 just mentioned have a teaching schedule of from 14 to 16 hours a week. However, there has undoubtedly been an improvement of late in this respect, and the average for all the 45 is about 11 hours per week, a figure that still leaves much to be desired. 
As to the preparation of those announcing graduate courses, it appears that nearly five-sixths have obtained the doctor's degree, and probably half of the remainder have had an equivalent training. The instructional force would thus seem to be well equipped. More than half have received training in European universities; a partial list of those who have spent at least one year abroad shows 50 who have studied in Germany, 14 in England, 5 in France, and 1 in Italy.

There is a marked tendency in some of the older universities to recruit their teaching staff from their own students. Even when a period of residence elsewhere has intervened such a practice has some disadvantages, but it also tends to give a permanent character to the work of the department.

\section{The Graduate Students.}

It may be said generally that the one prerequisite for status as a graduate student in an American university is the possession of a bachelor's degree. In many cases it is announced that this degree must have been given by an institution of equal rank, but as a matter of fact this stipulation is almost never enforced. The result of this is that there is no uniformity of preparation among those classed as graduate students, and frequently such men are taking work as elementary as the first course in the calculus. There are usually, however, more definite requirements to be fulfilled for admission to candidacy for a master's or a doctor's degree, but some institutions make no distinction of this sort and none require all graduate students to qualify as candidates for those degrees. In view of the wide range of attainment which presents itself among those classed as graduate students, statistics on this subject have only a relative value.

Another difficulty that arises is in the estimate of the work of the summer schools which have sprung up in the last fifteen years in connection with most of the larger institutions. Many of these have an attendance of from 5()0 to 1,500, a considerable proportion being teachers in secondary schools. The instruction is given by regular members of the university, or others specially engaged. The brief duration of these sessions, usually six weeks, and the fact that this is vacation work, very often brings about a serious lowering of standards. Usually, only a small amount of advanced work is offered, and the pub- 
lished lists of students give no clue as to the number taking mathematical courses. ${ }^{*}$ For this reason we shall here attempt to give no statistics as to graduate work in summer schools beyond the statement that ten institutions out of the twenty-four appear to give such courses, and that at least in two or three western institutions the enrollment in these classes is larger than the registration in regular advanced work.

The total number of graduate students in attendance on mathematical courses for more than one term or quarter of the year 1908-09 was probably about 400. The 24 institutions especially investigated report 295 , but many indicate only the department in which major work is carried, so that a considerable number specializing in physics and astronomy are not included in this figure. It is easier to obtain a fairly reliable estimate of how many have mathematics as their primary subject. The institutions mentioned report 225 , not including summer students and those enrolled for only one term or quarter. Possibly 25 more should be added for universities outside this list, making a total of 250 , a number less than twice that of instructors offering advanced courses. It may be interesting to note that 40 of the above-mentioned 225 were women. Only two of the leading universities now restrict their graduate attendance to men.

In this connection it would be highly desirable to present some statistics on the growth of graduate work in mathematics and its relation to the growth of graduate study in general. Unfortunately, little is to be found bearing on this point. In the report of the United States Commissioner of Education for the year 1896-1897 (volume 2, page 1649) the number of mathematical students in 24 institutions is given as 247 out of a total graduate enrollment of 3,204, but this probably includes summer registration and students specializing in other subjects. Since that time the number of graduate students in all departments has more than doubled, and mathematics would seem to have nearly kept pace with the general development. In 1904 the same authority (volume 2, page 1424) gives figures for ten

* The summer quarter at the University of Chicago differs considerably from the summer session in other institutions in that it is of equal duration with each of the otber three quarters, and is in other respects the same except in the character of the attendance. It is, however, divided into halves, and many students attend for six weeks only. It may be noted that the number of graduate students in mathematics enrolled in this one session is three times the average registration for any other quarter. 
institutions, showing 184 graduate students specializing in mathematics, inclusive of about 80 in summer sessions. This total has been increased by nearly 40 per cent in the last five years. It appears, however, that most of this recent growth has been confined to three or four institutions. Columbia reports an increase of over 300 per cent, and there has also been noteworthy development at the University of Illinois, large sums having been appropriated for the graduate school within the last two or three years.

Another indication of the increase of graduate students is afforded by a statement in the Bulletin of the American Mathematical Society (volume 16, number 2, page 95) in which the number receiving the doctorate in mathematics from American universities in each of the years 1899-1909 is given as, $13,11,18,8,7,14,21,11,13,22,15$. It may be noted that the average for the first three is nearly six-sevenths that of the last three. Since regulations affecting the doctor's degree are not generally more stringent than they were ten years ago, and no larger percentage of Americans are now studying abroad, these figures naturally lead one to inquire whether advanced work is really increasing as fast as the enrollment would indicate. It is possible that special courses for teachers have largely swelled the totals without materially adding to the amount of research. Another cause for the small and apparently decreasing percentage of doctorates may be the great demand for teachers of mathematics, due largely to the recent growth of technological work ; this pressure has probably led many to discontinue their studies earlier than they would otherwise have done. Some light is shed on this point by the fact that in the year 19081909 about sixty took the master's degree with mathematics as a major subject. Probably most of these had only that degree in view and terminated their graduate work as soon as it was obtained.

The bulk of advanced work is done by students receiving financial aid, or on salary as subordinate members of the teaching staff. To be more specific, out of the total of 225 in the institutions mentioned, 57 received fellowships and scholarships, paying from $\$ 100$ to $\$ 800$ per year, and 61 were assistants or instructors. We may safely assume that a considerable proportion of the remaining 107 were secondary teachers or others taking but one course. There would thus seem to be relatively few giving the major part of their time to study without remu- 
neration, and in fact only four institutions of the twenty-four have as many as six students of this class. The large number of assistants and instructors in graduate classes gives a hint of what is often a most unfortunate state of affairs. These are men who should be devoting all their time to graduate study, but they are usually so loaded down with class-work as to be unable to do justice to the courses they attempt to carry, and so poorly remunerated that they cannot save enough to provide for the additional year or two of research work necessary for the doctorate.

An examination of the migration of graduate students of mathematics develops some very interesting facts. In the institutions mentioned, 70 per cent received their bachelor's degree at another college or university, and about 50 per cent had not received their undergraduate training at any of the other places on that list. One may gather that there is no great disposition among students in universities maintaining advanced work to go elsewhere for further study after receiving the bachelor's degree, but that there is a large flow from the small colleges to the graduate schools. This movement is a source both of strength and weakness to the latter; of strength from the constant accession of fresh and in the main good material ; of weakness in that the preparation of many of these men is very defective. Only 25 per cent of the total enrollment had previously taken graduate work elsewhere, from which it appears that there is relatively little migration after graduate status has been attained.

\section{Courses of Instruction.}

Before considering specifically the nature and extent of the courses offered, we will briefly indicate the limitation of their field. Only two institutions have separate departments for applied as distinguished from pure mathematics. Another assigns applied mathematics to the department of astronomy, but it is more usual to include courses of this kind under the head of physics. Frequently the field of this latter department has no clear demarcation from that of mathematics; in general, courses in mechanics and mathematical physics are offered by both departments, with some resulting duplication. This report will cover only the work specifically listed as mathematics.

Courses beyond the first year in calculus are nearly always 
announced under two headings, introductory and advanced, often styled "For Undergraduates and Graduates," and "Primarily for Graduates," respectively. Although, as indicated by their title, courses of the former group are attended largely by undergraduates, a considerable proportion of the graduate enrollment is also to be found here, so that they properly form part of the field of the present report.

The American university is apt to be distinctly liberal in its announcements. Thus we find institutions with relatively small equipment offering from fifteen to twenty-five courses in the two groups, and in fact the average for the twenty-four mentioned is about twenty. It should be added that in many cases it is stated that these courses are offered in alternate years, but too frequently the lists are padded and no indication is to be found as to exactly what work was done in a given year. Something less than half the courses announced seem to have been conducted in 1908-1909, about one third of these being of the first group. We may note that the number of courses was thus about the same as that of graduate students, so that the average enrollment per class must have been very small.

The figures that have just been given clearly indicate the ambition of American universities to become centers of graduate study, and raise the question whether in many cases too much is not attempted on too little capital. It would seem that a concentration of advanced work in a dozen or so institutions would be a distinct gain, and that economy in the number of courses might in many cases be advantageously practiced. Often a course is given, not because it is needed, but in order that certain members of the department may participate in graduate instruction. There are, however, several institutions among the twenty-four mentioned which wisely limit their work to a fairly complete list of courses in the first group, with but four or five each year of the more advanced sort. In such cases an adequate training for the master's degree is aimed at, but students who wish to go further are urged to continue their work at one of the larger centers of graduate instruction.

Naturally there is much diversity in the classification of subjects under the two groups; thus we might expect Harvard, which encourages an unusual amount of specialization in the undergraduate program, to include in the first group such courses as quaternions and vector analysis, infinite series, special topics in higher algebra, and theory of numbers. Dif- 
ferential geometry is similarly classed at Yale, Michigan, and Wisconsin, as well as one or two other institutions, while about the same number place in this group a first course on the theory of functions.

As already indicated, much of the work in applied mathematics is left to the department of physics. This is particularly true of introductory courses. Only nine institutions of twenty-three whose practice was ascertainable announced under the head of mathematics a first course in analytic mechanics. Eight offered a second course in mechanics under the first group, but in only five cases was this given. It is, perhaps, more to be expected that celestial mechanics should be offered as a mathematical subject in but two institutions.

There is substantial agreement in classing the following subjects under the first group : advanced calculus, advanced analytic or projective geometry, solid analytic geometry, determinants and the theory of equations, and an introduction to differential equations. The first two are almost always full year courses while the others are more often of half that length. The extent to which these may be considered standard subjects is indicated by the fact that but one institution on the list fails to offer a course in advanced calculus, and in only one other instance was such a course not given, if we accept the evidence of catalogues; and practically the same is true of the second named subject. Three failed to offer the third and the same number the fourth as separate courses in the group, though we may suppose the subjects to have been included elsewhere, while the last was everywhere listed, either by itself, or in a few cases as the second half of the course in advanced calculus; and in only a few additional cases were these courses not actually given.

Though there is thus seen to be a considerable uniformity as to introductory subjects, it is interesting to note some of the variations from the more usual lists. Five courses in the history of mathematics are announced, three in probabilities and one in finite differences, six in statistics and insurance, and one in the theory of envelopes. Harvard and Iowa combine algebra with projective geometry, and as noted above, in some cases the first course in differential equations is given as a part of advanced calculus. There would thus seem to be evidence of a tendency to consolidate the introductory work into as compact a group as possible, and this tendency is probably on the increase. 
The establishment of special honors courses similar to those of Oxford and Cambridge has been much discussed of late, and has been recommended in recent reports of several university presidents, but so far Princeton and Columbia alone have adopted such a system. This movement, though of great interest, will not be further described here as it at present concerns undergraduates only.

In the consideration of the group of advanced courses it will be useful for some purposes to introduce what may appear to be an arbitrary distinction in classing institutions ; those which gave more than six courses of this kind will be placed together, while the others will be regarded as constituting another division. As a matter of fact, however, this corresponds to a real difference in the character of the work undertaken; the thirteen universities of the former class all have candidates for the doctor's degree among their students, while this is true of almost none of the others. As might be expected, a majority of the institutions giving more than six advanced courses are to be found among the older universities of the east.

As to subject matter, we may note that nearly everywhere far more emphasis is placed upon analysis than upon algebra, geometry, or applied mathematics. In but one institution of the first division are more courses given in any one of the last three subjects than in analysis, and the same is true of the class enrollment. As to the relative attention paid to the other branches, this varies widely, depending chiefly on the special interests of members of the department. Only two institutions of the first division leave all work in applied mathematics to other departments, and only two fail to offer courses in both geometry and algebra. We may conclude that there is generally a conscious effort to give a balanced curriculum, with especial emphasis on such subjects as the teaching staff is best prepared to offer. With institutions of the second division an even distribution of each year's work is, of course, impossible. Most of them, however, vary the courses given from year to year so as to include as wide a field as possible. In a few cases this seems to be only a matter of intention, and the courses actually conducted are confined to the subjects most interesting to the two or three men who have charge of graduate instruction.

All the universities of the first division include in their program from two to seven research courses or seminars, while 
none of the others has more than one. As this matter lies in the field of another committee, it will not be further discussed in this report.

Both in institutions of larger and of smaller equipment the practice of varying the program from year to year prevails. This is obviously a necessity where the enrollment is small. A number of the universities of the second division make it a rule never to repeat an advanced course in successive years, and this seems also to be true of at least three of the first group. In only two or three institutions are there more than four courses repeated year after year, and even in these cases the subject matter is seldom exactly the same. By far the most usual method of announcing courses consists in grouping them in pairs, sometimes from the same field but often widely differing in nature, offered by the same instructor in alternate years. Several institutions announce all of their work in this way. In a few cases more extended sequences are offered in which the cycle consists of more than two years. The effort thus shown to give variety to the work of the teaching staff and to cover as broad a field as possible is in the main most commendable, but it sometimes leads to the giving of advanced courses by men who may be qualified to do work in certain lines but are obviously unprepared for what they undertake.

Although there is a marked tendency not to devote whole courses to special topics, and one may note a certain conservatism in choice of subjects, most institutions offer at least one course in some comparatively narrow field, frequently one of recent development. Thus we find integral equations (given by three institutions) as well as point sets, divergent series, functional equations, modern theories in geometry, general analysis, differential invariants, linear systems of algebraic curves, imaginaries in geometry, symmetric functions, elasticity, and capillarity. Advanced courses in insurance, probability, and statistics appear in three announcements. In two instances the influence of Sylvester probably accounts for such subjects as the logic of mathematics, and principles of mathematics.

Although this may encroach somewhat on the field of another committee, we may at least mention here the courses offered specifically on the teaching of mathematics. As might be expected, these differ widely in nature. We shall not here enter into their character, but merely report that all but seven institutions of the list offer work of this kind. 
This section should not be concluded without some reference to the courses of lectures delivered by distinguished foreign mathematicians on various occasions within the last thirty years. It is true that comparatively few graduatestudents heard them, but the influence of Cayley's course has already been indicated, and the visit of Klein in 1893 was probably no less important. Of late a number of such courses have been given, and the exchange system may possibly lead to further developments along this line.

\section{Methods of Instruction.}

Practically all the work, both introductory and advanced, considered in the preceding section, is given by means of lectures of a little less than an hour in length. Sometimes seminars or research courses meet for two consecutive hours. By far the most usual program consists of three lectures a week, but three or four institutions prefer two-hour courses; very few classes meet but once a week, or oftener than three times.

A questionnaire on methods of instruction was sent to eighteen of the twenty-four institutions previously mentioned and replies were received from the following: Bryn Mawr, California, Chicago, Columbia, Cornell, Harvard, Illinois, Michigan, Missouri, Northwestern, Pennsylvania, Princeton, Wisconsin, and Yale. It appears that on some points there is a considerable diversity of practice, even among instructors in the same institutions, for freedom of instruction is, fortunately, almost everywhere carefully preserved. However, in most cases the answers received stated that the department used substantially uniform methods.

The first question concerned the assigning of courses to the members of the department, and was put in the form, - Are standard courses (the theory of functions, for example) given by the same or by different instructors each year? Only two answers indicated that the latter alternative was the rule. Two more, however, stated that a change in this direction was probable, while four indicated some variation in practice. The custom of permanently assigning certain fields to certain men thus seems to be distinctly in favor. In spite of the advantages of such a system it is undoubtedly true that in many cases it is carried too far, so that a subject comes to be considsidered a particular instructor's preserve, not to be trespassed upon.

An inquiry into the matter of examinations reveals two 
widely differing conceptions of graduate work. On the one hand the practice of Harvard, for instance, in requiring searching written examinations at the end of each semester indicates a general system of careful supervision, while Columbia, Princeton, Chicago, Bryn Mawr, and California, which, it seems, ordinarily give no course examinations, represent the opposite extreme where the student may take or leave the intellectual repast spread before him. Two or three other institutions allow oral examinations, and in some cases there is a difference of rigidity in the conduct of introductory and advanced courses. It appears that Yale, Harvard, Wisconsin, Northwestern, and Missouri represent the maximum of strictness in requiring written semester examinations. It is hard to determine any tendencies in this matter.

Another question that has a similar bearing concerns the giving of grades indicating excellence of work, a custom which prevails in undergraduate courses in American universities. The answers received show that the opposite practice is most usual in graduate work, but Harvard, Wisconsin, Chicago, Illinois, and Northwestern report that such grades are given.

To the query, - Are problems assigned for report from time to time? - an almost universal affirmative was returned, so that it would seem incorrect to conclude that anywhere is the student expected to be merely a hearer of lectures. It appears that in some courses in Columbia and Chicago this may have been the case, but the universal rule elsewhere is to require reports of some kind on assigned work. On the other hand stipulated reading in connection with courses is almost never insisted on. Lists of authorities and references are assigned but the responsibility for consulting these is thrown upon the student. Only three replies indicated an occasional exception to this rule, while but one or two stated that reports are required on such outside reading.

As already said, the work is given almost entirely in lectures, though only five replies indicated that text-books were never used. However, it would seem that they are followed in only a few introductory courses, and that even here they are used rather as reference books. Perhaps the most usual exception is in the tirst course in differential equations. The replies received were unanimous in stating that there were no courses in which a text-book was used exclusively, no lectures being given. 
It is customary to devote some hours, or parts of hours, to reports of students and discussion of lectures. However, at Harvard reports are given in seminars only, while at Princeton and Northwestern they are very infrequent. Yale, California, and Cornell do not give class time to discussion of lectures, though the last named appoints regular hours for individual consultation. At Wisconsin oral quizzes on lectures are a feature. The most usual practice everywhere is to allow a few minutes of each hour for discussion, questions being frequently asked in interruption of a lecture. The instructor's procedure is as a rule quite informal. In some cases an hour is reserved once a week or twice a month for discussion and reports.

In addition to the regular lecture and seminar courses, some institutions maintain courses for reading and research, in which the student (usually there is but one) meets the instructor at intervals for report and consultation, but no stated lectures are given. Often, but not always, this is done in connection with the writing of a thesis. Harvard announced eight such courses last year, Cornell two, Michigan two, and Missouri one. In the last two cases only were written examinations given, but in all but two courses problems were assigned for report.

Work in absentia has decreased almost to the vanishing point, Chicago alone conducting a few graduate courses by correspondence.

A number of the larger institutions are well supplied with models, calculating machines, and other mathematical apparatus, but others are more meagerly equipped. In several cases the making of models has had a place in graduate instruction.

A special feature at Yale has been the writing up of lecture notes by students and placing them for reference in the seminar room. This practice has been followed elsewhere for certain courses, but does not seem to be the rule in any other institution.

In the main it would appear that little change in methods is contemplated, and certainly no general movement is on foot. Two or three institutions have inaugurated considerable departures from past usage, but this is in each case an individual matter due to changes in the personnel of the department.

\section{Requirements for the Master's Degree.}

The master's degree "in course" is given by practically all American colleges and universities as representing one full 
year of graduate study.* The title of Master of Arts or of Science is also given as an honorary distinction under entirely different conditions, but we will here consider only the degree "in course." This is sought especially by students who either have but one year to devote to advanced work or are not sure of being able to continue for the doctorate, since its possession is often a decided advantage in obtaining a teaching position. Even in secondary work the master's degree is frequently insisted on, and this tendency is so marked that in the opinion of many it will before long be as much in demand there as the doctor's degree now is for the candidate for a college position.

Excluding varieties of nomenclature corresponding to technical or professional courses, four master's degrees are given, namely, Master of Arts, Master of Science, Master of Philosophy, and Master of Letters, but of the last two the former is conferred by but three institutions of the twenty-four previously referred to, and the latter by only one. Nearly half give the master's degree in arts only. The distinction is, except in a few instances, an artificial one in that it does not indicate the candidate's field of advanced work, but merely shows which bachelor's degree he has received. It is noteworthy that in eleven institutions of the twenty-four this distinction has been abandoned, and even where the degree in science is preserved it is often possible for any who prefer it to receive the arts degree provided their work is not mainly professional or technical.

As noted on page 236, about sixty master's degrees were conferred on students specializing in mathematics in the year 19081909 , a number but little less than one-fourth the total graduate enrollment in that subject. Of the twenty-four institutions especially considered, only five or six failed to confer the degree in that year. Two institutions, Harvard and Columbia, gave the maximum number, eight each.

The universal condition for admission to candidacy is the possession of a bachelor's degree from an institution of equivalent standing. Although there is some latitude in the interpretation of this rule, it is but fair to say that the student admitted with inferior preparation is usually required to make up his

\footnotetext{
* Johns Hopkins University seems to be alone in requiring two years. Bryn Mawr gives the degree to no students who have done their undergraduate work elsewhere, except as an accompaniment to the doctor's degree.
} 
deficiencies, taking a longer period than the minimum of one year for obtaining the degree. Applications for candidacy accompanied by a program of studies must usually be filed early in the first semester and must be approved either by a committee of the faculty, or by the dean of the graduate school. In case a thesis is required, the subject must be submitted soon after admission to candidacy. The number of courses which must be carried varies from three to five, but in the latter case an allowance is made for the thesis. Some of this work may be done in summer school, and in a number of institutions the degree may be obtained by attendance on three or four such sessions, with the usual requirements as to examination and thesis. Correspondence study or work in absentia has nearly disappeared so far as mathematics is concerned, though some catalogues still announce that part or all of the requirements may be thus met by students who have previously been in attendance. In a few cases where five three-hour courses must be carried a deduction is made for advanced work taken by the student as an undergraduate, but in excess of the requirements for the bachelor's degree. A combination with professional work is sometimes possible, but in the case of mathematics this must be confined chiefly to teaching and engineering.

In 1904 a committee, after two years' consideration and careful inquiry, reported to the Chicago Section of the American Mathematical Society on the requirements for the master's degree, with especial reference to conditions in western institutions. We will here use their recommendations, which, they state, correspond with the requirements at several leading American universities, as a basis for discussing present conditions. Their findings will, however, be only briefly summarized, since the details are easily accessible.*

The first questions raised are, - What should be the minimum acceptable time devoted to undergraduate mathematics, and how should it be distributed? - The committee agrees that this should be the equivalent of five three-hour courses carried continuously throughout the four years of the undergraduate course, and distributed about as follows: In preparation for the calculus (algebra, trigonometry, and analytic geometry), five year-hours ; calculus, including differential equations and mechanics, six hours; advanced algebra and geometry, four hours. It will be noted that this list includes

* Published in the Bullerin, 2d ser., vol. 10, No. 8 (1904), pp. 380-385. 
seven year-hours in courses classed as " introductory" in section V. Courses in applied mathematics are not specifically recommended, though it is urged that undergraduate instruction maintain a close contact with the physical sciences. Except that four undergraduate courses are more usually taken as a minimum, and that the exact distribution here shown is not always insisted on, it may fairly be said that the stronger institutions at present comply very closely with the above conditions.

The next section of the report reads: "Upon the basis of the preparation indicated above, it is the opinion of the committee that the work leading to the master's degree should include at least 270 hours * selected from the following groups of subjects. The selection should in any case include subjects from at least two of the three groups.

I. GEOMETRY.

Projective geometry.

Modern analytic geometry, algebraic curves and surfaces. Application of calculus to twisted curves and surfaces. (Differential geometry.)

Solid analytic geometry.

Descriptive geometry. (Darstellende Geometrie.)

II. Analysis.

Theory of equations.

Advanced calculus.

Theory of functions.

Differential equations.

Theory of numbers.

Invariants.

III. Applied Mathematics.

Analytic mechanics.

Mathematical astronomy.

Mathematical physics.

Mathematical theory of probability.

"This arrangement provides that the candidate, in case he enters upon his graduate work with the minimum mathematical preparation indicated above, and hence having a broader general training in his undergraduate course, should be required to take at least two thirds of his year's graduate work in pure and

* The term hour here refers to a single lecture hour, so that the above is equivalent to two and one half three-hour year courses. 
applied mathematics. On the other hand, as it may be assumed that the student entering upon his graduate work with a larger mathematical credit than this has had less general training in his undergraduate course, it is the opinion of the committee that he should be permitted to take as much as one half of his work in departments other than mathematical, providing, however, that the minimum requirement in mathematics indicated above is also fulfilled."

Present practice tends to reduce somewhat the minimum here recommended, so that in a majority of the larger universities two courses in mathematics are accepted, though as a matter of fact more are usually taken. Four institutions require a candidate to present three subjects and two others require work in at least one additional department. The majority would seem to permit the student to take all his work in mathematics if he so chooses, but with one or two exceptions there seems to be no institution where this is distinctly encouraged. No general rule obtains as to the distribution of the candidate's work; this is nearly always an individual matter decided by the instructor or committee in charge. It is probable, however, that the recommendation presented above represents nearly the average of practice.

An interesting variation from ordinary requirements is presented by the University of Michigan. In addition to "Plan A," which calls for the usual amount of specialization, a scheme styled "Plan B" allows a wider choice of studies. Here the thirteen hours to be taken may be distributed as is seen fit among three departments, and other requirements would seem to be less rigid, but the year's work will not usually count as one of the two or three necessary for the doctor's degree.

It is apparently nowhere stipulated, except at Bryn Mawr, where unusual conditions obtain (see footnote, page 245), that the candidate be able to read a foreign language. The report under consideration recommends a knowledge of German and considers French also desirable. As a matter of fact the requirements for the bachelor's degree are such that nearly every graduate has had at least one year's work in one of these languages, but seldom enough to make reading easy. Nevertheless, in most cases some reading of foreign mathematical texts is urged, though rarely required.

The committee quoted believe that all candidates should present a thesis, but that this need not embody original research. 
It appears that thirteen institutions of the twenty-four adhere strictly to this rule, while in at least five more the requirement is optional with the instructor in charge or the head of the department. In three or four others a thesis is never presented for the master's degree.

The last topic considered is that of examinations. The report mentioned recommends either a final test covering all the graduate courses taken by the student, or the requirement that a high grade be obtained in term examinations in each course. The former alternative is the more usual one, - in fact it obtains at eighteen of the twenty-four institutions considered, while in several of the others either procedure is possible. At Harvard one of the two highest of the four passing grades in each course is the sole requirement. The final examination may be either oral or written, - practice seems to be fairly evenly divided in this matter, - and if oral, it is usually conducted by a committee of instructors from the departments involved.

There are smaller and less reputable institutions in which the requirements are lower, and in fact some where all requirements are merely nominal. The present report has aimed only to present the state of affairs in the institutions which are really prepared to confer the degree.

\section{GEOMETRIC TRANSFORMATIONS.}

Geometrische Transformationen. Zweiter Teil: die quadratischen und höheren birationalen Punkttransformationen. By KarL Doenlemann, associate professor of mathematics at the University of Munich. Leipzig, Göschen (Sammlung Schubert, XXVIII), 1908. viii +328 pages and 59 figures.*

AT the time this volume was written there was no book devoted to the subject of its title. The next year appeared the fourth volume of Professor Sturm's treatise $†$ and several parts of the Encyklopädie, so that now we are fairly well supplied with an introduction to this most fundamental study. And the two books do not overlap; the larger work is synthetic and replete with geometric illustrations, while that under review is

\footnotetext{
* The first part of Professor Doehlemann's treatise appeared in 1902 ; it was reviewed in the Buslatin by Professor Gale (vol. 10, pp. 512-515).

† See the review in the Bulletin, volume 17 (1910), pp. 150-154.
} 